\title{
ERRATUM
}

Satoshi Ikeda • Takao Ito • Makoto Sakamoto

\section{Erratum to: Discovering the efficient organization structure: horizontal versus vertical}

Erratum to: Artif Life Robotics (2010) 15:478-481

DOI 10.1007/s10015-010-0844-1

The correct versions of Figs. 3, 5-8 are shown below.

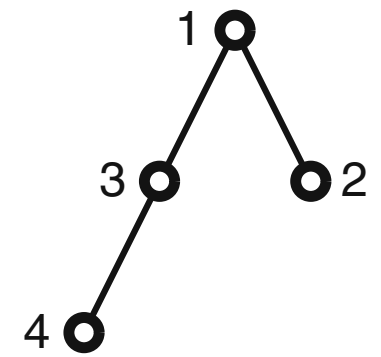

Fig. 3. An efficient tree for $\left\{\sum,\left\{\phi_{i}\right\}_{i=1,2}\right\}$

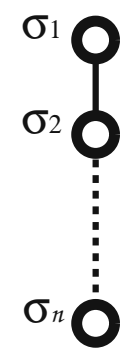

Fig. 5. $T_{\sigma_{1}}$ as a path graph

The online version of the original article can be found under doi: $10.1007 / \mathrm{s} 10015-010-0844-1$

S. Ikeda $(\varangle) \cdot$ M. Sakamoto

Department of Computer Science and Systems Engineering,

University of Miyazaki, 1-1 Gakuen Kibanadai-nishi, Miyazaki

889-2192, Japan

e-mail: bisu@cs.miyazaki-u.ac.jp

T. Ito

Department of Business Administration, Ube National College of

Technology, Ube, Japan

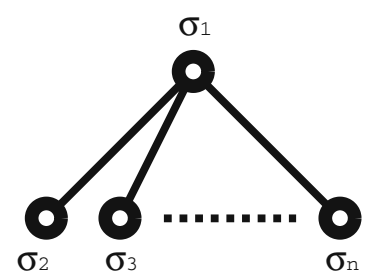

Fig. 6. $T_{\sigma_{1}}$ as a star graph

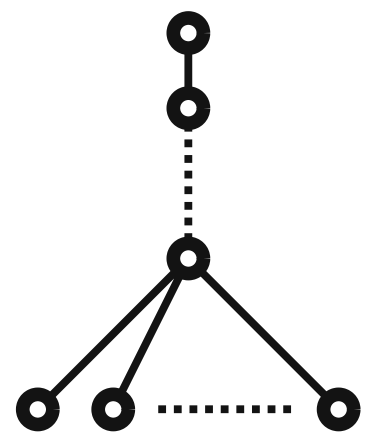

Fig. 7. General form of an efficient tree

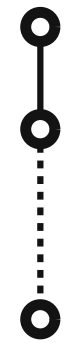

(a) $\# D_{3}=0$

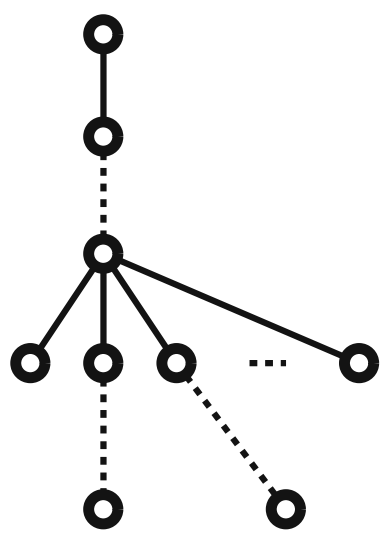

(b) $\# D_{3}=1$
Fig. 8. Two kinds of possible form. (a) $\# D_{3}=0$. (b) $\# D_{3}=1$ 